\title{
TCEC Cup 1
}

Article

Accepted Version

The TCEC Cup 1 official report

Haworth, G. and Hernandez, N. (2019) TCEC Cup 1. ICGA Journal, 41 (1). pp. 31-38. ISSN 1389-6911 doi: https://doi.org/10.3233/ICG-190099 Available at https://centaur.reading.ac.uk/80284/

It is advisable to refer to the publisher's version if you intend to cite from the work. See Guidance on citing.

Published version at: https://content.iospress.com/articles/icga-journal/icg190099

To link to this article DOI: http://dx.doi.org/10.3233/ICG-190099

Publisher: The International Computer Games Association

All outputs in CentAUR are protected by Intellectual Property Rights law, including copyright law. Copyright and IPR is retained by the creators or other copyright holders. Terms and conditions for use of this material are defined in the End User Agreement.

\section{www.reading.ac.uk/centaur}

\section{CentAUR}

Central Archive at the University of Reading

Reading's research outputs online 


\section{TCEC Cup 1}

Guy Haworth and Nelson Hernandez ${ }^{1}$

Reading, UK and Maryland, USA

After successfully copying the divisional league structure of other sports and games, the TCEC organisation introduced a knockout event, the TCEC Cup, which took place October $5^{\text {th }}-21^{\text {st }}, 2018$, a two-week 'Wimbledon' pause between TCEC13's Division P and Superfinal.

The event was fully seeded on TCEC13 results, and Fig. 1 depicts the logos of the engines in seed order. Basic engine details have been published elsewhere (CPW, 2018; Haworth and Hernandez, 2019a) but some fifteen engines as indicated in Fig. 2 were upgraded for the Cup, a testimony to the energy and enthusiasm of their authors. The format was of 8-game matches at the Rapid tempo of $30^{\prime}+10^{\prime \prime} / \mathrm{m}$, the opening being repeated with colours reversed after every odd-numbered game. The first four ply were defined from a set of 504 openings, chosen at random by the second author here, their relative frequency reflecting that seen in human play. Decided matches were truncated and tiebreaks were resolved by further pairs of games, unusually at the same tempo and with no Armageddon backstop.
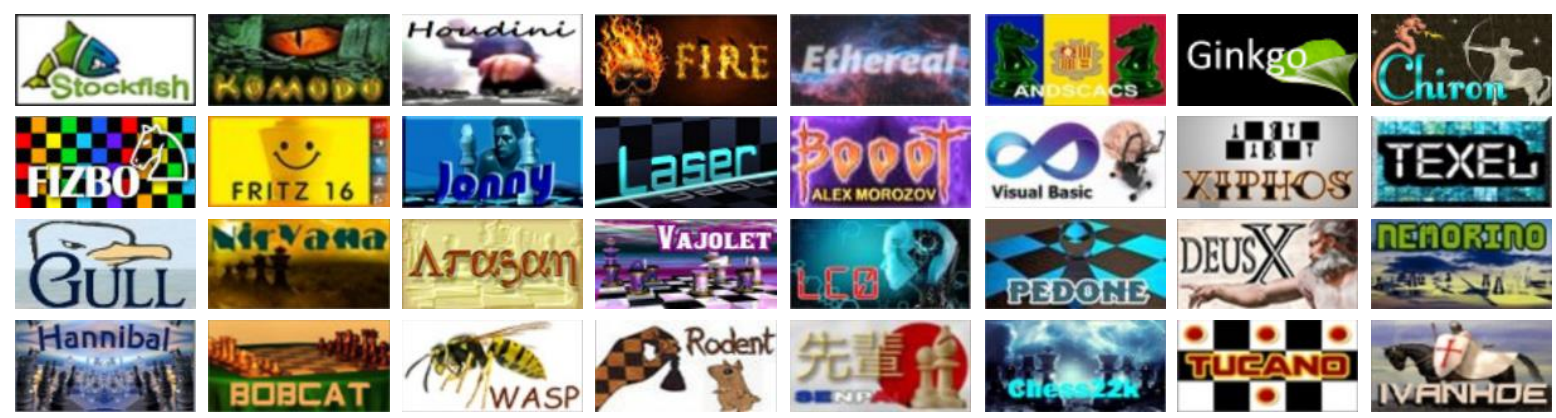

Fig. 1. Logos for the TCEC Cup engines in their seeded order (STOCKFISH $\rightarrow$ KOMODO $\rightarrow \ldots \rightarrow$ IvANHOE).

The competitors were bracketed together in the most popular way, the one that defers confrontation between higher seeds to retain audience interest. It also rewards past success with marginally easier opponents. These two criteria define the pairings in what is known as standard, distant or balanced seeding (Karpov, 2015; Schwenk, 2000). Fig. 2 lists the competitors with their current division, '5' indicating demotion from TCEC Division 4. In the listing of Fig. 2, the highest seed is systematically first in its respective half, quarter, etc. of the list. Flipping subsets of the 31 brackets provides $2^{31}-1$ other listings of the same pairings ${ }^{2}$ but few have any underlying rationale. Fig. 2 also reports game-results from the winner's point of view. The asterisked engine played White first but as there was no learning within the tournament, this conferred no advantage.

\footnotetext{
${ }^{1}$ Corresponding author: g.haworth@ reading.ac.uk

${ }^{2}$ It is interesting, if irrelevant, to see Euler's Mersenne Prime $2^{31}-1$ of 1772 (Haworth, 1987) in this context.
} 
Chess engines' performances are not affected by many of the issues that bear down on their carbon counterparts: not for them the financial, personal, social or societal issues which afflict us. One might therefore expect them to perform to their ratings and recent form. However, TCEC was successful in encouraging half of the authors to provide engine upgrades: at least DEUSX, ETHEREAL and 'LC0' LEELA CHESS ZERO were known to be developing in a major way. The head-to-head format, relatively rapid tempo and two new Google V100 GPUs also made results less than totally predictable. Where then would matches be unexpectedly close: where would there be significant upsets to the seeding?

\begin{tabular}{|c|c|c|c|c|c|c|c|c|}
\hline \# & 局 & $\begin{array}{c}\text { Elo } \\
\Delta\end{array}$ & Elo & & 胥 & Round 1 Pairings & Round 1 Results & Round 2 \\
\hline \multirow{2}{*}{01} & $\checkmark$ & 403 & 3519 & $\mathrm{P}$ & 01 & Stockfish 270918 & Stockfish. 5-0: 11111 & \\
\hline & & & 3116 & '5' & 32 & Ivanhoe $999946 h^{*}$ & & Stockfish* (01) - Gull (17) \\
\hline \multirow{2}{*}{02} & & 20 & 3197 & 2 & 16 & Texel 1.08a11* & Gull $4 \frac{1}{2}-21 \frac{1}{2}:===11=$ & Stockfish, 41/2-1/2: $1111=$ \\
\hline & & & 3217 & 2 & 17 & Gull 180521 & & \\
\hline \multirow{2}{*}{03} & & 173 & 3354 & 1 & 08 & Chiron S13.2* & Chiron, $4 \frac{1}{1} 2^{-2} 2^{1 / 2}: 1=1====$ & \\
\hline & $\checkmark$ & & 3181 & 4 & 25 & Nemorino 5.05 & & Chiron* (08) - Fizbo (09) \\
\hline \multirow{2}{*}{04} & & 96 & 3265 & 1 & 09 & Fizbo 2 & Fizbo, 6-4: $0===110=11$ & Chiron, $4 \frac{1}{2}-2-1 / 2$ : $====1=1$ \\
\hline & $\checkmark$ & & 3169 & 3 & 24 & Hannibal 20180922* & & \\
\hline \multirow{2}{*}{05} & & 331 & 3393 & $\mathrm{P}$ & 04 & Fire 7.1 & Fire $5-0 \cdot 11111$ & \\
\hline & $\checkmark$ & 然 & 3062 & 4 & 29 & Senpai $2.0^{*}$ & H & Fire* (04) - Booot (13) \\
\hline \multirow{2}{*}{06} & & 62 & 3246 & 1 & 13 & Booot 6.3.1* & Boogt 41/2-31/v =-=-1=-= & Fire, 5-2: $1====11$ \\
\hline & $\checkmark$ & 02 & 3184 & 3 & 20 & Vajolet2 2.6.1 & D000, T/2-J/2. - & \\
\hline \multirow{2}{*}{07} & & 320 & 3350 & $\mathrm{P}$ & 05 & Ethereal 11.06* & Ethereal 5-0: 11111 & Ethereal* $(05)$ - LC Zero (21) \\
\hline & 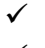 & & 3030 & 4 & 28 & Rodent III 1.0.171 & & Leela Chess Zero, 81/2-71/2 \\
\hline \multirow{2}{*}{08} & $\checkmark$ & 6 & 3241 & 1 & 12 & Laser $250918^{*}$ & LC Zero $5-3 \cdot=====11$ & $=1==0===,=======1$ \\
\hline & 1 & & 3247 & 3 & 21 & Leela Chess Zero 18.11248 & & \\
\hline \multirow{2}{*}{09} & & 55 & 3475 & $\mathrm{P}$ & 02 & Komodo $2135.10^{*}$ & Komodo 5-0: 11111 & \\
\hline & $\checkmark$ & JJ & 2919 & '5' & 31 & Tucano 7.06 & & Komodo (02) - Xiphos* (15) \\
\hline \multirow{2}{*}{10} & $\checkmark$ & 85 & 3245 & 2 & 15 & Xiphos 0.4.2* & Xiphos $41 / 2-1^{1 / 2}:==111=$ & Komodo , $41 / 2-21 / 2:=1===1=$ \\
\hline & & & 3160 & 2 & 18 & Nirvana 2.4 & & \\
\hline \multirow{2}{*}{11} & & 241 & 3340 & 1 & 07 & Ginkgo $2.12 *$ & Ginkgo, 41/2-11/2: $1===11$ & \\
\hline & & & 3099 & 3 & 26 & Bobcat 8 & & Ginkgo* (07) - Fritz (10) \\
\hline \multirow{2}{*}{12} & & 32 & 3244 & 1 & 10 & Fritz $16.10^{*}$ & Fritz, $4 \frac{1}{2}-3 \frac{1}{2} 2: 1==0===1$ & Ginkgo, $41 \frac{1}{2}-1 \frac{1}{2}:=11==1$ \\
\hline & $\checkmark$ & & 3212 & 3 & 23 & DeusX 1.1 & & \\
\hline \multirow{2}{*}{13} & & 419 & 3491 & $\mathrm{P}$ & 03 & Houdini 6.03 & Houdini, 5-1: =1=111 & \\
\hline & $\checkmark$ & & 3072 & 4 & 30 & chess $22 \mathrm{k} 1.11^{*}$ & & Houdini* (03) - Arasan (19) \\
\hline \multirow{2}{*}{14} & & 54 & 3258 & 2 & 14 & ChessBrainVB 3.70* & Arasan, 51/2-41/2:0====1==,1= & Houdini, 5-1: $1=1=11$ \\
\hline & $\checkmark$ & & 3204 & 3 & 19 & Arasan TCEC13.2 & & \\
\hline \multirow{2}{*}{15} & & 375 & 3339 & $\mathrm{P}$ & 06 & Andscacs 094030 & Andscacs, 5-0: 11111 & \\
\hline & $\checkmark$ & $3 / 2$ & 2964 & 4 & 27 & Wasp $3.3^{*}$ & Anuscacs, J-0. 11111 & Andscacs (06) - Jonny* (11) \\
\hline \multirow[t]{2}{*}{16} & & 53 & 3250 & 1 & 11 & Jonny $8.1^{*}$ & Jonny, 5-2: =11===1 & Andscacs, 5-3: $=1=====1$ \\
\hline & $\checkmark$ & J & 3197 & 3 & 22 & Pedone 1.9 & & \\
\hline
\end{tabular}

Fig. 2. Round 1 and 2 results from the winner's perspective: the asterisked engine had White in game 1.

\section{$1 \quad$ Round 1}

The action opened with an unsurprising whitewash by the TCEC Grand Champion STOCKFISH: seeds 2, 4, 5 and 6 later emulated this feat. A minor upset of the seeding, if not of the ELO ratings, came in the second match, TEXEL-GULL. Four draws between them in TCEC13 Division 2 had given few clues. 
With the score at 2-4, GULL got across the line after defending a drawn KNPPKRP endgame for nearly 100 moves. It is not clear why TEXEL finally gave in by capturing into an adjudicated KRPKNP draw. Whether TCEC should add selected 7-man EGTs (de Man et al, 2018) to the 'adjudication set' is an open question of value and cost. The FIZBO-HANNIBAL match featured the first turnaround, tie and successful comeback: $1 \frac{1}{2}-2 \frac{1}{2} 2$ became $3 \frac{1}{2}-2 \frac{1}{2}$ and $4-4$. The first pair of games were decisive: $6-4$. HANNIBAL put up a great fight and would have won without its 'technical break' loss in game six. This game was clearly drawn at the time (Haworth and Hernandez, 2019b).

Laser-LC0 saw the first eagerly awaited contest in this event between a classic 'Shannon AB' and an 'ANN' artificial neural network engine. The online audience figure shot up from 500 to 850. LC0 was much better than its TCEC13 seeding suggested and its ELO reflected the evident self-training benefit of many millions of games. The engines were inseparable until LC0 uncorked two remarkable wins to triumph 5-3 and provide the first major upset. 'Kingscrusher' (2018) provided an excellent commentary for games 7 and 8. This win set up an ETHEREAL-LC0 encounter for Round 2 for which, if this had not been the web, there would have been a queue round the block for tickets.

Down the card, ARASAN became the third to confound the seeding, beating CHESSBRAINVB 51/2-41/2 after the longest and most closely fought match of the round. Twelve hours play produced a second tie and successful comeback. This was perhaps the most surprising of the underdog wins.

\section{Round 2}

The seeding question now focused on the engines in TCEC13 Division P: would they all survive to the quarterfinals? STOCKFISH and CHIRON progressed very much as their rating advantage (Labelle, 2018) suggested they would. Neither match was in any doubt: 5-0 and 41/2-1/2 respectively.

The ETHEREAL-LC0 match was a different matter entirely: it deserved its prime-time slot in the programme. Against ELO expectations, ETHEREAL was on the wrong end of the first four games, losing game two and saving the others only with accurate endgame play fully informed by the 6-man EGTs (de Man et al, 2018). Game five saw a comeback, courtesy of the controversially favourable 'Elephant Gambit', a 1000:1 random selection: this gave White an initial advantage of nearly +1 . However, in game six, not only did LC0 fail to build on this advantage but ETHEREAL was again able to defend a rook ending, a pawn down for 60 moves. The match was tied at 3-3 and moved on, via perpetual check in game seven with both engines running on fumes, to a 4-4 tie.

The engines then remained locked in combat for seven more draws, taking us into day two of this epic encounter. LC0 was certainly winning on points in boxing terms and could have won game 14 from position 94w (Müller and Haworth, 2019; Romero, 2012). Finally, with viewer numbers up to 1250, LC0 won game 16 and punctured the seeding after ETHEREAL played 6. ... Qxb2?, already known to the second author's own statistics as losing. This was by far the standout match of the tournament to date. The clash of two machine architectures produced extraordinary play from both sides.

FIRE-BOOOT was inevitably a case of 'after the Lord Mayor's show' - a relatively mundane affair. After an opening 1-0 win for FIRE, four draws went by before FIRE won with Black, the first such win for some 14 games. KOMODO-XIPHOS continued in the same vein, 41/2-21/2, as did GINKGO-FRITZ, 41/2-11/2, and HOUDINI-ARASAN, 5-1. This last was however a notably strong performance from HOUDINI. In the last match, ANDSCACS needed the full ration of eight games to get past the spirited defence of JONNY. 


\section{The quarter-finals, semi-finals and final}

All but one of the top eight seeds survived as in Fig. 3, the absentee being ETHEREAL which arguably had drawn the short straw by having to meet LC0. The latter was the only engine to have lost a game so far, that being the controversial 'Elephant Gambit' game 5 in the previous round.

As a form guide, we have the TCEC13 Division P results to help us. There, the top three seeds had all won their eight-game matches against their Cup opponents, 6-2, 7-1 and 41/2-31/2 respectively. Even so, Mark Lefler had already flagged that KOMODO was handicapped by inefficient initialisation, an issue belatedly solved in the lab. FIRE-LC0, was now expected to be the pick of the matches and was given extra time in the schedule. FIRE, on the basis of TCEC results, stood only marginally better than ETHEREAL which put up such a great fight in Round 2 against LCO.

\begin{tabular}{|c|c|c|c|c|c|c|c|c|}
\hline \# & $\stackrel{\Xi}{g}$ & $\begin{array}{c}\text { Elo } \\
\Delta\end{array}$ & Elo & $\dot{\vec{a}}$ & छ్ & Engines & Quarter-final & Semi-final \\
\hline \multirow{2}{*}{01} & $\checkmark$ & 165 & 3519 & $\mathrm{P}$ & 01 & Stockfish* 270918 & Stockfich $41 / 21 / 0 \cdot 11-11$ & \multirow{4}{*}{$\begin{array}{l}\text { Stockfish* }(01)-\operatorname{LC} 0(21) \\
\text { Stockfish, } 4 \frac{1}{2}-2-1 / 2:====1=1\end{array}$} \\
\hline & & & 3354 & $\mathrm{P}$ & 08 & Chiron S13.2 & Stockt1sh, 41/2-1/2: $11=11$ & \\
\hline \multirow{2}{*}{02} & \multirow[b]{2}{*}{$\checkmark$} & \multirow{2}{*}{146} & 3393 & $\mathrm{P}$ & 04 & Fire 7.1 & \multirow{2}{*}{$\begin{array}{l}\text { Leela Chess Zero, 11-9: } \\
=110===0,====10====11\end{array}$} & \\
\hline & & & 3247 & 3 & 211 & Leela Chess Zero* 18.11248 & & \\
\hline \multirow{2}{*}{\multicolumn{2}{|c|}{03}} & \multirow{2}{*}{135} & 3475 & $\mathrm{P}$ & 02 & Komodo* 2135.10 & \multirow{2}{*}{ Komodo, 41/2-11/2: $111===$} & \multirow{4}{*}{$\begin{array}{l}\text { Komodo* }(02)-\text { Houdini }(03) \\
\text { Houdini, 41/2-31/2: } 11==0==\end{array}$} \\
\hline & & & 3340 & 1 & 07 & Ginkgo 2.12 & & \\
\hline \multirow{2}{*}{\multicolumn{2}{|c|}{04}} & & 3491 & $\mathrm{P}$ & 03 & Houdini 6.03 & \multirow{2}{*}{ Houdini 41/2-21/2:===1=1= } & \\
\hline & & & 3339 & $\mathrm{P}$ & 06 & Andscacs* 094030 & & \\
\hline
\end{tabular}

Fig. 3. Quarter- and semi-final results from the winner's perspective.
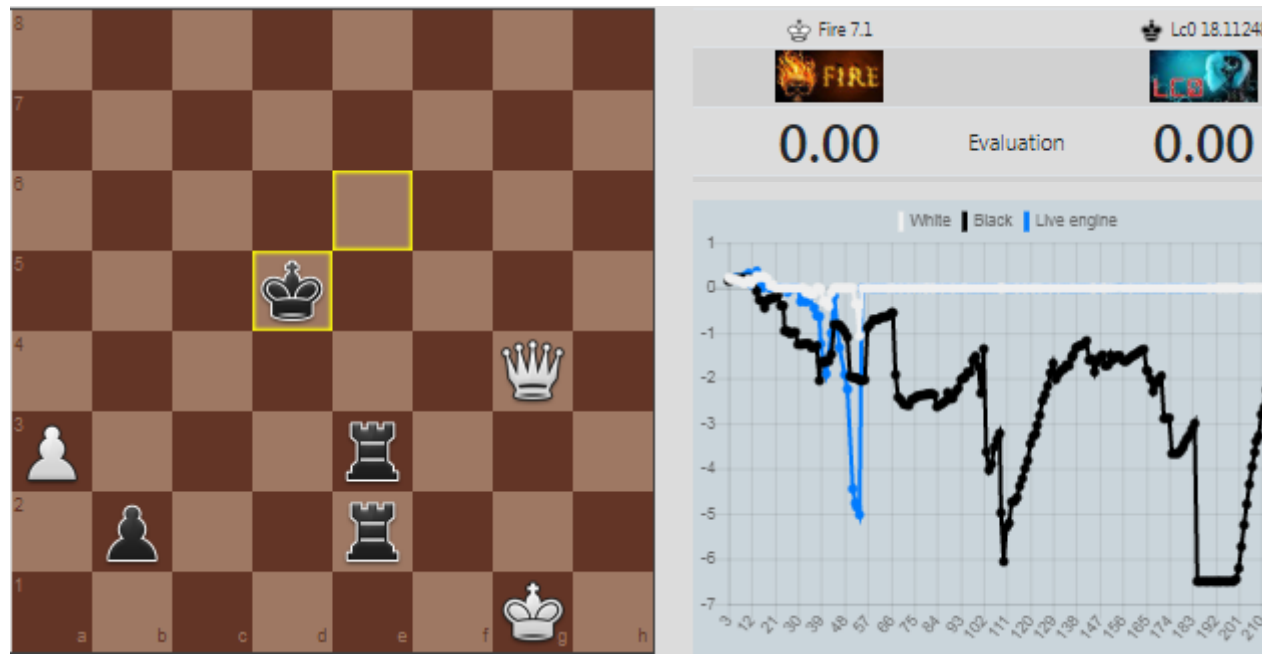

Whine | Elack | Lwe engine

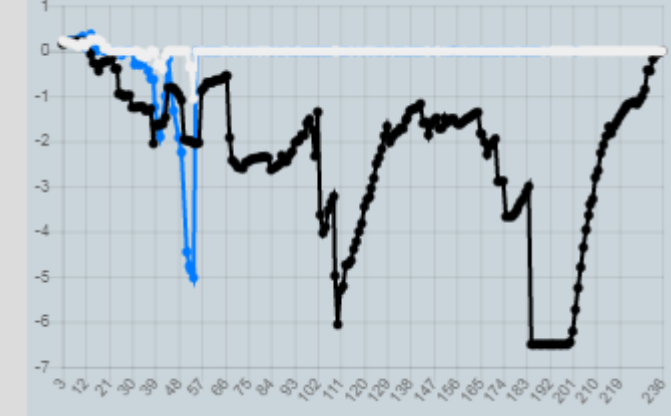

Fig. 4. FIRE-LC0, game 10. Kibitzing STOCKFISH's evaluation, ‘draw', agrees with FiRE’s from position 47b.

Once again, STOCKFISH sailed through undefeated, 41/2-1/2 against CHIRON. FIRE-LC0 did not disappoint the record crowd and started with a bang: LC0 scored two quick wins. Undeterred, FIRE was the first engine to close a two-point gap, following a loss in game three with a win in 'return game' four and a win at the last gasp in game eight. Extra time beckoned with no penalty shoot-out on the agenda. Game 10 owed its 236-move length to LC0 not recognising that its attack would be unavailing: what else was 
LC0 missing in the endgame? FIRE and side-evaluator STOCKFISH, running on 88 threads and with 7man EGTs, were unanimous that game 10 was draw from position $47 \mathrm{~b}$ to the end, see Fig. 4. Games 11-12 were also drawn but games 13-14 were both won by White, only the second time this has happened in this event. After four more draws, LC0 surprisingly won both sides of an ECO A05 Reti Opening, 1. Nf3 Nf6 2. Nc3 Nc6 3. d4 d5 4. Bf4, to close out the match. This extraordinary 'AB versus MCTS' encounter broke and held the records for longest match, most games and longest game. It also demonstrated the different styles of position-evaluation, move ranking and play.

In the other half of the draw, KOMODO scored heavily and quickly against GINKGO as in TCEC Division P: $4 \frac{1}{2}-1 \frac{1}{2}$, one click better than the form guide. HOUDINI was heading for a 1-0 win in game two against ANDSCACS when the TCEC server crashed: the game was restarted at move one rather than at the position and with the clocks reached: HOUDINI only drew but did win games four and six.

The semi-finals therefore featured the top three seeds, who had not lost a single game between them, and the dark horse LEELA CHESS ZERO which had successively edged out the $12^{\text {th }}, 5^{\text {th }}$ and $4^{\text {th }}$ seeds. This performance alone suggested that LC0 would surely promote to TCEC Division P shortly.

The first semi-final was fully expected to be long, given that the two previous LC0 matches had both lasted longer than a day. The first quartet of games were indeed drawn though STOCKFISH thought LC0 had a distinct advantage around move 90 in game four. The break came in game five: LC0 castled Kside into the aim of STOCKFISH's double-barrelled and perfectly aimed bishops, a risk which required accurate play. 12. ... Re8? immediately triggered a swift and classic attack removing the King's defences in surgical fashion. LC0's queen could only look on from a distant hill on a5 as Black fell apart in both positional and material terms across ten short moves. This was brutal, surprising and certainly shocking, given LC0's previous play in this event. STOCKFISH also won game seven after LC0's somewhat inexplicable 59.... Qxa2?: once again, it won the match without losing a game.

\begin{tabular}{|c|c|c|c|c|c|}
\hline$\#$ & 胥 & $\begin{array}{c}\text { Elo } \\
\Delta\end{array}$ & Elo 斊㤩 & Engines & The Final \\
\hline \multirow{2}{*}{01} & $\checkmark$ & \multirow{2}{*}{28} & $\begin{array}{lll}3519 & \mathrm{P} & 01\end{array}$ & Stockfish* 270918 & \multirow{2}{*}{ Stockfish, $41 / 2-31 \frac{1}{2}$ : ======1= } \\
\hline & & & $\begin{array}{lll}3491 & \mathrm{P} & 03 \\
\end{array}$ & Houdini 6.03 & \\
\hline
\end{tabular}

Fig. 5. The STOCKFISH - Houdini final: STOCKFISH wins after a single, dramatic breakthrough in game seven.

The final could equally have been a long affair in terms of games if not length of games. STOCKFISH and HOUDINI were closely matched but perhaps the recent update to STOCKFISH made the difference. There was only one decisive result and this came in game seven, again surprisingly quickly rather than after a long, attritional battle. Arguably, the crucial mistake was 20. ... g5, overlooking the Knightsacrifice 21. Nxg5 which took out two pawns and destroyed Black's King safety. 21. ... fxg5 22. Qg3 Kh8 23. Qxg5 Qxc3 24. e5 followed and, as above, Black's Queen was elsewhere when needed.

So, the favourite, STOCKFISH, won but not without having to face its most likely future challenger, LEELA CHESS ZERO.

\section{A summary}

The TCEC Cup gave us the opportunity to watch extended head-to-head matches between engines, separated or not in TCEC13, matches which occasionally had to be prolonged to find a winner. The 
remarkable progress of LC0, which surely surprised even its large fan-base, raised lots of talking points. If it has progressed from its recent TCEC Division 3 level of play to beat two Division P engines, even before TCEC13 has ended, how far will it progress in the future? Can its apparent weakness in endgames be eradicated? What constitutes a level playing field when the server platform offers two distinct types of processor? Are the Nvidia (2018) GPUs unfairly outpowering the CPUs?

A few words are in order about TCEC's policy with regard to openings, one which aims to increase the variety of the chess exhibited and reduce the draw percentage while preserving fairness on a level playing field. This last consideration was addressed in a natural way by having each engine play both sides of the same four-ply opening without the benefit of learning. Just as a good golf hole should give the chance of a birdie to the brave, the chess opening should increase the opportunity for one side to win but not make it so easy that both sides win. Table 1 indicates the extent to which the goals of the opening choices were achieved: in $37.9 \%$ of 108 game-pairs, the score was $1 \frac{1}{1} 2^{-1 / 2}$.

Table 1. Counts of the game-pair results.

\begin{tabular}{|c|c|c|c|c|c|c|c|c|c|c|c|c|c|c|c|c|c|c|}
\hline \multirow[t]{2}{*}{ \# } & \multicolumn{2}{|c|}{ R1 sequences } & \multicolumn{2}{|l|}{ R1 pairs } & \multirow{2}{*}{$\frac{\%}{0.0}$} & \multicolumn{2}{|c|}{ R2 sequences } & \multicolumn{2}{|l|}{ R2 pairs } & \multirow{2}{*}{$\frac{\%}{0.0}$} & \multicolumn{2}{|c|}{ Q/S/F seqs. } & \multicolumn{2}{|l|}{ Q/S/F pairs } & \multirow{2}{*}{\begin{tabular}{l|}
$\%$ \\
6.9
\end{tabular}} & \multicolumn{2}{|l|}{ Total pairs } & \multirow{2}{*}{$\begin{array}{c}\% \\
1.9\end{array}$} \\
\hline & & 0 & & & & & & م & & & 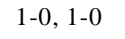 & ? & 1 & 0 & & $1-0$ & 2 & \\
\hline & & 4 & & 13 & 2 & $1 / 2-1 / 2$ & 6 & $1-0 \& 1 / 2-1 / 2$ & 12 & .4 & & 3 & & 7 & 41 & & 2 & 29. \\
\hline & & 7 & 1 & 17 & 34.0 & & $\begin{array}{l}3 \\
0\end{array}$ & 1 & 3 & 10.3 & & 1 & & 4 & 8 & -1 & 24 & 22. \\
\hline 4 & $-1 / 2$ & 16 & & 16 & 32.0 & $1 / 2-1 / 2$ & 11 & & 11 & 37.9 & $1 / 2^{-1 / 2}$, & 14 & & 14 & 48.3 & $1 / 2-1 / 2$ & 41 & 38. \\
\hline 6 & $0-1,0-1$ & 0 & $1 \& 0-1$ & 0 & .0 & $0-1,0-1$ & 0 & $1 \& 0-1$ & 0 & 0.0 & $0-1,0-1$ & 0 & $-1 \& 0-1$ & & 0. & $-1 \& 0-1$ & 0 & 0.0 \\
\hline
\end{tabular}

Table 2. The shortest and longest 1-0, drawn and 0-1 games in each phase of TCEC Cup 1.

\begin{tabular}{|c|c|c|c|c|c|c|c|c|c|c|c|c|c|c|c|c|c|c|}
\hline \multirow{2}{*}{ Rnd } & \multicolumn{6}{|c|}{$1-0$} & \multicolumn{6}{|c|}{$1 / 2-1 / 2$} & \multicolumn{6}{|c|}{$0-1$} \\
\hline & \multicolumn{3}{|c|}{ Shortest } & \multicolumn{3}{|c|}{ Longest } & \multicolumn{3}{|c|}{ Shortest } & \multicolumn{3}{|c|}{ Longest } & \multicolumn{3}{|c|}{ Shortest } & \multicolumn{3}{|c|}{ Longest } \\
\hline 1 & $33 / 4$ & $\mathrm{Fi}-\mathrm{Se}$ & 23 & $99 / 3$ & Jo-Pe & 117 & $46 / 4$ & Lc-La & 26 & $44 / 2$ & $\mathrm{Ca}$ & 208 & $9 / 4$ & Tu-Ko & 36 & $19 / 7$ & Lc & 79 \\
\hline QF & $1 / 1$ & $\mathrm{Ch}$ & 26 & $8 / 3$ & $\mathrm{Lc}-\mathrm{Fi}$ & 80 & $32 / 1$ & An-Ho & 25 & $20 / 15$ & $\mathrm{Lc}-\mathrm{Fi}$ & 246 & $27 / 2$ & Gi-Ko & 57 & $2 / 2$ & $\mathrm{Ch}-\mathrm{St}$ & 84 \\
\hline SF & $5 / 5$ & $\mathrm{Lc}$ & 29 & $9 / 2$ & -Ko & 76 & $14 / 7$ & $\mathrm{Ho}$ & 51 & $1 / 1$ & -Lc & 136 & $8 / 1$ & Ко-Но & 61 & $8 / 1$ & Кo-Ho & 61 \\
\hline F & 111 & St-Ho & 22 & $7 / 7$ & Ho & 22 & $5 / 5$ & St-Ho & 34 & $3 / 3$ & t-Ho & 223 & - & - & - & - & - & - \\
\hline
\end{tabular}

More complete data and pgn files, extended by engines' Principal Variations and by our analyses, are available (Haworth and Hernandez, 2019b): they should lead readers to their particular interests whatever they are - shortest/longest games as in Table 2, openings/endgames, asymmetry and so on. For example, the sidelines associated with LC0's missed KQPPPKQPP win in Round 2, game 14 (Müller and Haworth, 2019) are included. As for the endgame, some 73 games, 32\% of the 227, reached 7-man territory where the 'EGT' endgame tables provide benchmark perfection. In all cases, the game result was the theoretical value: 58 draws and 15 wins. Here in Table 3, we merely note the residual sub-8-man mates that were in effect assumed to be won by the TCEC adjudication rules.

This TCEC Cup event attracted informed and helpful video commentary from 'GM TheChessPuzzler' (2018) and 'Kingscrusher' (2018). 'GM' covered 'r.g' games 1.50/56/68, 2.24/35, QF.25, SF.5/9 and F.7. 'KC' covered games 1.49/50, 3.24/25 and 4.5/7. Both featured quite a few LC0 games. The online audience was in the 350-1250 range and many were knowledgeably kibitzing on the chat line. Sideevaluations by a 128-thread STOCKFISH (Costalba, 2018; de Man, 2018) with 7-man EGTs (de Man and 
Guo, 2018) and by LC0 (Linscott, 2018) also underlined the fact, if this were needed, that different engines can evaluate positions very differently. It would be good to have the latest 'AB' and 'MCTS' engines commenting at the same time.

Table 3. The fifteen sub-8-man residual mates of TCEC Cup $1 .^{3}$

\begin{tabular}{|c|c|c|c|c|c|c|c|c|c|c|c|c|c|c|c|c|c|c|c|}
\hline \multirow{2}{*}{$\#$} & \multirow{2}{*}{$\dot{\vec{E}}$} & \multirow{2}{*}{ 芯 } & \multirow{2}{*}{ hite } & \multirow{2}{*}{ lack } & \multirow{2}{*}{ 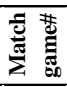 } & \multirow{2}{*}{$\begin{array}{l}7 \mathrm{~m} \\
\text { pos. }\end{array}$} & \multicolumn{2}{|c|}{ Th. dtm } & \multirow{2}{*}{\multicolumn{2}{|c|}{$\begin{array}{r}\text { dtc dtz } \\
\text { plies } \\
\end{array}$}} & \multirow{2}{*}{ Phase } & \multirow{2}{*}{$\begin{array}{l}\text { 6-7m } \\
\text { pos. }\end{array}$} & \multirow{2}{*}{$\begin{array}{c}\text { Next } \\
\text { endgame }\end{array}$} & \multirow{2}{*}{ FEN } & \multicolumn{4}{|c|}{ Th. dtm dtc dtz } & \multirow{2}{*}{-Res. } \\
\hline & & & & & & & V & & & & & & & & Val. & & plies & & \\
\hline 01 & 1 & 34 & Senpai & & 05 & $49 b$ & $0-1$ & 91 & 1 & 1 & 1 & $50 w$ & KQPKRB & $6 \mathrm{k} 1 / 8 / 7 \mathrm{~B} / 1 \mathrm{p} 5 \mathrm{q} / 8 / 8 / 4 \mathrm{RK} 2 / 8 \mathrm{w}$ & -1 & 90 & 58 & 2 & $0-1$ \\
\hline 02 & 1 & 5. & & & 05 & $58 w$ & -0 & 75 & $J$ & 5 & - & & & & -0 & 2 & & 6 & 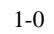 \\
\hline 04 & 1 & 10 & & & 05 & $\mathrm{~b}$ & -1 & 75 & 35 & 1 & & $75 w$ & & & -1 & 00 & 4 & 8 & $0-1$ \\
\hline 05 & 2 & 0 & & & 04 & $68 \mathrm{~b}$ & $0-1$ & 45 & $9 ?$ & 1 & 然 & $71 \mathrm{~b}$ & & & $0-1$ & 61 & 33 & 3 & $0-1$ \\
\hline 06 & 1 & 5 & & & 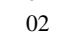 & & & $c^{2}$ & 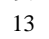 & & & & & & & & & - & $0-1$ \\
\hline 09 & 1 & 104 & & & 然 & & $0-1$ & 47 & 9 & 7 & 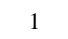 & & KRPPKRP & & $0-1$ & 47 & 9 & 7 & $0-1$ \\
\hline 10 & 1 & 107 & & & 0 & & $1-0$ & 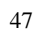 & $\mathrm{J}$ & 3 & 3 & & RP & & -0 & 47 & $J$ & 3 & $1-0$ \\
\hline 11 & 1 & 01 & & & 01 & $53 \mathrm{~b}$ & $0-1$ & 47 & 1 & 1 & 1 & $54 w$ & & & $0-1$ & 46 & 16 & 4 & $0-1$ \\
\hline 12 & 2 & 02 & & & 02 & $77 w$ & $0-1$ & 62 & 18 & S & 14 & $84 w$ & КРРКВР & 年 & $0-1$ & 44 & 12 & 2 & $0-1$ \\
\hline 13 & 1 & 92 & HIasc & alnv & 06 & & $1-0$ & 43 & 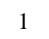 & 1 & 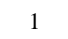 & 960 & & & $1-0$ & 42 & 2 & 2 & $1-0$ \\
\hline
\end{tabular}

Training run 1

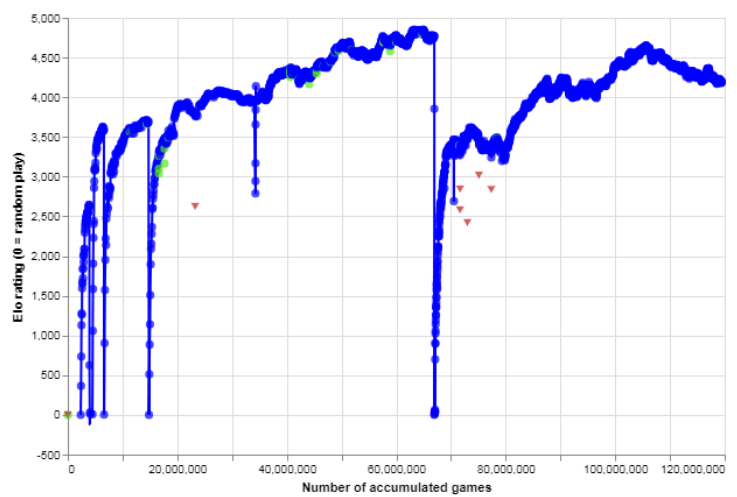

Training run 2

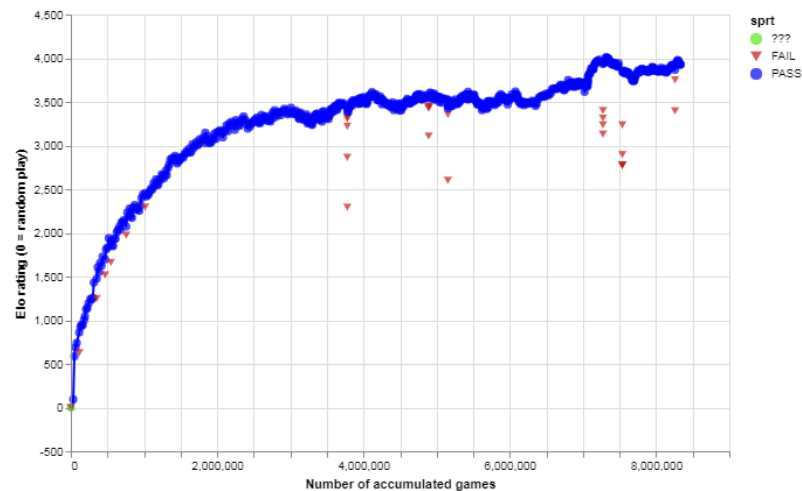

Fig. 6. Training Leela Chess Zero: ELO progress.

Congratulations to the TCEC Cup winner STOCKFISH and to the other quarter-finalists, the expected HOUDINI and KoMODO plus, see Fig. 6, the rising star LEEla CHESS ZERO (Linscott, 2018). Congratulations also to the TCEC team who wrestled down the financial and technical challenges of putting on this event and to all supporters who helped them.

The TCEC Cup knockout format at its Rapid tempo has proved very popular and will surely feature again in the TCEC schedule.

\footnotetext{
${ }^{3}$ Our thanks to Yakov Konoval (2018) for the 'DTC' Depth to Conversion depth figures.
} 


\section{REFERENCES}

Costalba, M. (2018). https://github.com/official-stockfish. STOCKFISH community on Github. CPW (2018) https://tinyurl.com/icga046. Biographies of chess engines, authors and developers. de Man, R. (2018) https://github.com/syzygy 1/Cfish. CFISH: C port of STOCKFISH. de Man, R., Fiekas, N. and Guo, B. (2018). https://tinyurl.com/icga007. Fiekas' interface to 'Syzygy formatted' de Man sub-7-man and Guo 7-man DTZ 50 " EGTs.

de Man, R. and Guo, B. (2018). ftp://112.73.74.24/pub/syzygy/. Sub-8-man DTZ5" EGTs.

GM Thechesspuzzler (2018). https://tinyurl.com/icga053. Nine video commentaries.

Haworth, G. McC. (1987). http://centaur.reading.ac.uk/4571/. Mersenne Numbers.

Haworth, G. $M^{\mathrm{c}} \mathrm{C}$. and Hernandez, N. (2019a). http://centaur.reading.ac.uk/78820/. TCEC13: the $13^{\text {th }}$ Top Chess Engine Championship. ICGA Journal, Vol. 41(2), 92-99. Doi: 10.3233/ICG-190103.

Haworth, G. Mc C. and Hernandez, N. (2019b). http://centaur.reading.ac.uk/80284/. TCEC Cup 1. This note plus statistics and pgn files. ICGA Journal, Vol. 41(1) 31-38. Doi: 10.3233/ICG-190099.

Karpov. A. (2015). https://tinyurl.com/icga051. A theory of knockout tournament seedings. University of Heidelberg, Dept. of Economics, Discussion Paper 600.

'Kingscrusher' (2018). https://tinyurl.com/icgaj010. Six 'KC' LC0 video commentaries.

Konoval, Y. (2018). Private communication of DTC(onversion) depths for some positions.

Labelle, F. (2018). tinyurl.com/icgaj016. ELO performance calculator.

Linscott, G. (2018). https://github.com/LeelaChessZero/lc0/wiki LC0 on Github

Müller, K. and Haworth G. MC. (2019). http://centaur.reading.ac.uk/80432/. FINALGEN revisited: new discoveries. ICGA Journal, Vol. 41(1), 53-60. Doi: 10.3233/ICG-190095.

Nvidia (2018). https://www.geforce.co.uk/hardware/desktop-gpus. Nvidia desktop GPUs.

Romero, P. P. (2012). https://tinyurl.com/icga013. FINALGEN, endgame analysis software.

Schwenk, A.J. (2000). What is the Correct Way to Seed a Knockout Tournament? Amer. Math. Monthly 107(2), 140-150. doi: 10.1080/00029890.2000.12005171. 


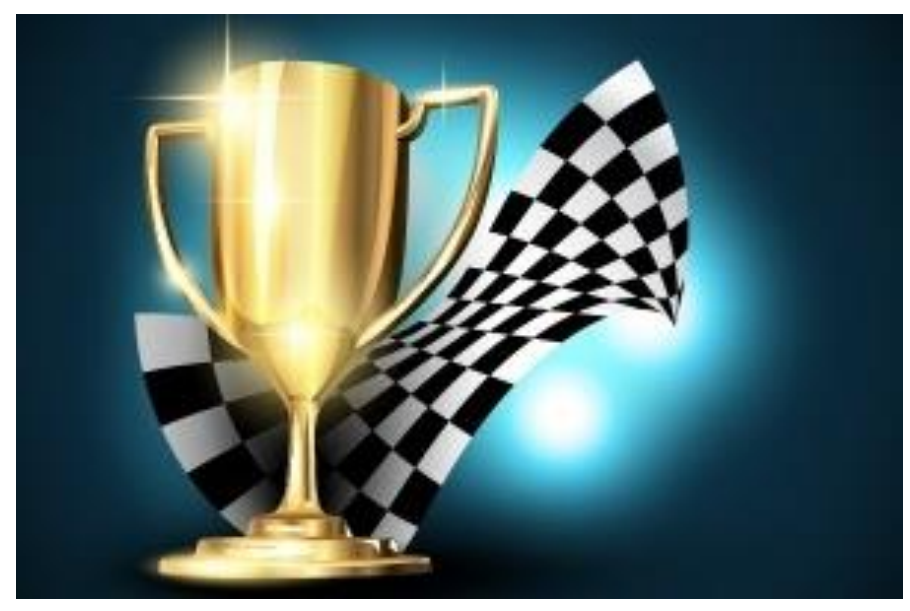

Fig. 7. The TCEC Cup, to be inscribed. 